\title{
AOR
}

Selected Papers of \#AolR2019: The $20^{\text {th }}$ Annual Conference of the Association of Internet Researchers Brisbane, Australia / 2-5 October 2019

\section{CHEMSEX: DIGITAL, CHEMICAL AND COMMUNAL INFRASTRUCTURE OF DISINHIBITION}

Since the early days of digital media studies, it has been widely understood that trust in digital technologies has been indispensable for the operation of queer communities (Campbell, 2004; Correll, 1995; Mowlabocus 2010). In networking otherwise spatially disparate subjects whose desires fall outside heteronormative acceptability, digital infrastructures have become key sites in contemporary gay culture where the everyday fight for queer life is struggled over. More broadly, disinhibition plays a central role in queer world-making: letting go of fear and coming "out"; "losing yourself" through dancing; and by chemically altering your state of mind through alcohol and drug consumption. Recently practices like these have been transformed through the everyday use of digital media platforms. This panel explores such 'digital infrastructures of disinhibition' through a sexual practice that has attracted significant attention over the last decade: 'chemsex', when gay and bisexual men use locative social media such as hook-up apps to organise group sex encounters where the recreational drugs crystallized methamphetamine, GHB/GBL and/or mephedrone are consumed.

To fully understand the emergence of chemsex this panel argues that we must turn our attention to the multiplicity of technologies that sustain it. Chemsex is a socio-sexual practice that to an overwhelming degree is constructed, negotiated, enacted, maintained and critiqued via digital platforms. Specifically, news media outlets have been instrumental in the spread of a chemsex panic. Hook-up apps are key to facilitating chemsex encounters because they allow for instant access to nearby subjects who can join the chemsex event; And porn platforms lend their affordances to its visual consumption. At the same time as digital media intervenes in chemsex subjectivity, so do the above mentioned drugs. Instead of treating the "effects" of media and drugs on the participating bodies as separated elements, this panel explores what can be achieved analytically if we think of them as co-constituting chemsex. To do so we conceptualize contemporary gay sociability as depending on digital, chemical, and communal infrastructures (Race, 2018); as an upshot of the ways media, medicine and recreational drugs, but also material social spaces like gay clubs, are practiced, policed and transformed. Here, trust is understood as emerging in relation to the affordances of digital platforms, media discourse on chemsex, the chemical capacities

Suggested Citation (APA): Hakim, J., Møller, K., Florêncio, J., Murphy, D., Race, K., Pienaar, K., \& Lea, T. (2019, October 2-5). Chemsex: Digital, Chemical and Communal Infrastructure Of Disinhibition. Panel presented at AolR 2019: The $20^{\text {th }}$ Annual Conference of the Association of Internet Researchers. Brisbane, Australia: AolR. Retrieved from http://spir.aoir.org. 
of drugs to produce altered states, and the physical space in which men can have or negotiate sex.

Concretely, the individual panel contributions explore the role of digital infrastructures at a variety of scales and sites. In their paper, Jamie Hakim understands chemsex in the UK as a response to the neoliberal assault on gay men's collective modes of being after the 2008 financial crisis. In interviews with 15 gay and bisexual men, they discovered that gay men were using digital platforms such as Grindr, Spotify, Uber and porn sites to create affectively intense chemsex encounters because the night life spaces where they had historically 'felt together' had closed due to gentrification.

Moving to look at the ways chemsex is part of digital visual culture and the platformification of it, Kristian Møller's paper uses visual ethnography to study chemsex visual and communicative culture on the porn platform Pornhub.com, and an online conferencing service. They find normative and counterpublic trust-risk chemsex configurations at play and suggests these are often at odds and that the different digital affordances iframe what kinds of pleasures can be had in materially significant ways.

On the basis that contemporary financial capitalism attempt to calculate futures algorithmically, João Florêncio's paper investigates the openings chemsex encounters us to imagine. Using speculative pragmatism (Race, 2018), the paper examines "pig play" - a formation that resists the notion of trust being undone by all kinds of violation, to argue that certain kinds of boundary-breaking are key to understanding chemsex sociabilities and intimacies and that chemical alterations play a performative part in this process.

Finally, in their paper, Dean Murphy, Kane Race, Kiran Pienaar \& Toby Lea consider how PrEP - drugs to prevent acquiring HIV infection - is making new realities for those who had previously been unable to participate in the kinds of sexualised drug use and digital spaces and practices associated with chemsex. Moving beyond the commonplace concerns of health discourse, the paper suggests that PrEP is now part of chemsex realities and is transforming how chemsex matters and to whom. In doing so, they affirm rather than disavow the moralistic framing initially used to disqualify PREP from respectable discourse.

\section{References}

Campbell, J. E. (2004). Getting it on online. Cyberspace, gay male sexuality, and embodied identity. New York: Routledge.

Correll, S. (1995). The ethnography of an electronic bar: The Lesbian Cafe. Journal of Contemporary Ethnography, 24(3), 270-298.

Mowlabocus, S. (2010). Gaydar culture: gay men, technology and embodiment in the Digital Age. Farnham: Ashgate.

Race, K. (2018). The Gay science: intimate experiments with the problem of HIV. London \& New York: Routledge. 



\section{CHEMSEX: DIGITALLY-MEDIATED QUEER MODES OF TRUST DURING THE POST-2008 CONJUNCTURE}

Jamie Hakim

University of East Anglia, UK

Over the last decade the UK has witnessed the growth of chemsex. This paper seeks to understand why. It does so by approaching chemsex 'conjuncturally' (Hall et. al., 1978) and situating it within its historically specific conjunctural relations - ideological, technological, social, cultural, political and economic. In using this approach, and by drawing on original interviews with 15 men who have engaged in chemsex, this paper argues that chemsex is best understood as a digitally mediated 'queer mode of trust' between gay and bisexual men that has emerged precisely in response to historical conditions where trust has been all but eroded by neoliberalism's continued hegemony in the UK after the 2008 financial crisis.

Chemsex was first reported to the UK's National Health Service in sufficient numbers to warrant a coordinated response in 2011 (Bourne et al., 2014). This places its emergence within the post-2008 conjuncture. Beginning with the failure of the neoliberal economic system in the $2007 / 2008$ financial crisis, this conjuncture has been defined by neoliberalism's redoubling as a hegemonic project under the sign of 'austerity'; or the ideological insistence on competitive individualism as the privileged mode of being in the world to legitimate the movement of wealth redistributed to Labour during post-war social democracy back to Capital (Harvey, 2005) through the erosion of the welfare state. This post-2008 redoubling of neoliberalism is unthinkable without the digital. The widespread use of web 2.0, social media platforms, smartphones and 3G/4G

accessibility during this period has endowed neoliberalism with new methods of capital accumulation and labour exploitation (Srnicek, 2017) that, in the context of UK austerity, have directly contributed to a steep increase in structural inequality. At the same time digital media have also been used to resist neoliberalism- e.g. their use in anti-austerity political organisation (Gerbaudo, 2018). It will be argued in this paper that chemsex provides an example of digital media being used to offer a reprieve from neoliberalism in how they have offered a group of people left alienated by neoliberalism's assault on their collective modes of being, the means to 'feel together' (Gilbert, 2013) in affectively intense, and otherwise difficult to experience, ways.

Though practiced by gay and bisexual men throughout the UK, the majority of chemsex activity has been mostly concentrated in London (Bourne et. al., 2014). Like digital media, both gay men and London have been particularly important to neoliberalism's struggle for hegemony. Since the 1990s, gay men have been successfully incorporated into the neoliberal project, on the condition they relinquish the collective organising that formed the basis of queer politics in favour of marriage and consumption as the only legitimate forms of sociality (Duggan, 2003). London has played a similarly central role to neoliberalism's hegemonic efforts. Margaret Thatcher's deregulation of the financial markets in 1986 reinvigorated the city's economy after its post-industrial decline contributing to the opening up of previously depressed parts of London to gentrification. One of the chief victims of London's gentrification has been the city's LGBTQ+ nightlife 
scene. Between 2006 and 2017 there has been 58\% reduction in the amount of the city's LGBTQ+ spaces (Campkin and Marshall, 2017), significantly diminishing the physical spaces where these communities have collectively gathered. During the same time period geo-locational smartphone hook-up applications, such as Grindr (2009-) and Scruff (2010-) - whose platforms network spatially proximate users and allow them to send each other texts and images - have become one of the most popular ways for gay and bisexual men to organise their sexual, romantic, and social lives. It is in the convergence of these historical processes that we find the conditions of possibility for the emergence of chemsex. Hook-up apps have provided gay and bisexual men with tools to organise collective encounters at precisely the time that collectivity as both a political ideal to strive for, as well as the physical spaces in which it might flourish, are under assault by neoliberalism's post-2008 redoubling. In this sense, we see digital media being used to offer a reprieve from neoliberalism's continued struggle for hegemony.

That chemsex is a desire for collectivity that has been actualized by digital media, became clear through the interviews I have conducted with men who engage in chemsex. One of the surprising findings from the interviews was that sex was not the only focus of a chemsex encounter. The overriding effect of consuming chemsex drugs was a 'loss of inhibitions'. This loss of inhibitions did lead to uninhibited group sex but it also led to intimate group conversation, dancing and collectively browsing the internet, whether that be for music to listen to, pornography to watch or more men to invite over to the session. It was the fact of being together in affectively intense, sexual and nonsexual ways, that gives chemsex its specificity. Chemsex, therefore emerges as a particular manifestation of Race's assemblage of chemical, digital and communal infrastructures that provides ways of feeling together for a group of people left alienated by both neoliberalism's interpellative address as well as its assault on the material spaces in which they have historically gathered.

In making this argument, this paper also contributes to wider debates on the relationship between hook-up apps and neoliberalism. Some scholars have argued that by extending market logics to the field of intimacy hook-up apps have become tools of neoliberal subjectification (e.g. Roach 2015). The use of hook-up apps in the context of chemsex shows the opposite can also be true. Bearing this in mind, recent popular media debates that distrust the ability of gay and bisexual men to use hook-up apps to forge 'authentic' intimacy miss the bigger picture. If some gay men have been positioned as ideal neoliberal subjects, and the ideal form of relationality under neoliberalism is competitive individualism and therefore an ontological distrust of the other, it is neoliberalism that constrains the formation of relationships of trust between gay men and not the hook up apps they use to form them. In the context of chemsex then, hook-up apps can be seen as a site where digitally mediated modes of queer trust are produced, during a moment whose conjunctural arrangements make the formation of trust all but impossible for everybody.

\section{References}

Bourne, A., et al. (2014). The chemsex study: drug use in sexual settings among gay \& bisexual men in Lambeth, Southwark \& Lewisham. London: Sigma Research, London 
School of Hygiene \& Tropical Medicine. Available from: www.sigmaresearch.org. uk/chemsex [Accessed 23 October 2015].

Campkin, B., and Marshall, L. (2017). LGBTQ+ Cultural Infrastructure in London: Night Venues, 2006-present. Available from: https://www.ucl.ac.uk/urbanlab/docs/ LGBTQ_cultural_infrastructure_in_London_nightlife_venues_2006_to_the_present. pdf [Accessed $1 \overline{6}$ September 2017].

Duggan, L. (2003) The twilight of equality?: neoliberalism, cultural politics and the attack on democracy. Boston, Mass.: Beacon Press.

Gerbaudo, P. (2018) The Digital Party: political organisation and online democracy. London: Pluto Press.

Gilbert, J. (2013). Common ground: democracy and collectivity in an age of individualism. London: Pluto Press.

Hall, S., et al. (1978). Policing the crisis: mugging, the state and law and order. Basingstoke: Macmillan.

Harvey, D. (2005). A brief history of neoliberalism. Oxford: Oxford University Press.

Roach, T. (2015) "Becoming Fungible: Queer Intimacies in Social Media." Qui Parle: Critical Humanities and Social Sciences, 23 (2): 55-87. 


\title{
(COUNTER)PUBLIC CHEMSEX IMAGINARIES ON A PORN PLATFORM AND A VIDEO CONFERENCING SERVICE
}

\author{
Kristian Møller \\ IT University of Copenhagen, Denmark
}

Chemsex as a practice mobilises intense affect. In the media, it typically operates as an 'unhappy object' (Ahmed, 2009) to which fear of death, biomedical anxiety of pureness, and narratives of trauma sticks. Conversely, engaging in the disinhibition that chemsex promises constitutes a counterpublic (Warner, 2002) that works to defy the recurring problematization of chemically enhanced erotic encounters (Macfarlane, 2016). This paper approaches the ways chemsex is practiced with digital media, and how the digital porn and communication platforms for circulating representations affect the formation of an erotic chemsex imaginary. Notably, anxieties, risk, and modes of trust are not absent from chemsex practices and imaginaries, but rather co-constitutive of its pleasures.

By focusing on mediated chemsex I seek to avoid the containment of it as a social phenomenon that only works on certain queer bodies made vulnerable due to some presumed trauma or moral weakness. Instead the paper reveals the erotic imaginary of chemsex and what it makes digitally available for playful consumption to a range of people and publics wider than that suggested by the ongoing medical, digital, and sexual panic focusing on "problematic" use (Platteau et al., 2019).

The paper compares how chemsex imaginaries unfold on the sometimes Do-It-Yourself (DIY) porn platform Pornhub, and on a conference call service (service name redacted of ethical concerns). Further, by studying mediated chemsex we gain insight into presumably the ways in which chemsex practically figures in the most people's lives: Not, or rarely, in physically co-present encounters of chemsex, but as synchronous or asynchronous mediated experiences that may or may not involve using drugs yourself. With media playing such a big part in chemsex' social life we should consider how the different digital infrastructures provide the means for chemically enhanced sexual practice to become visible and consumed by anyone with internet access, while also activating the semantic and distributive capacities of those infrastructures to allow for disinhibited pleasures to emerge in the first place.

Ideals of trust are key to understanding the separation of distinct chemsex imaginaries. To Savransky, trust is not one thing that is either there or not there, felt by its presence or absence. Rather he asks that we explore what "different modes of thinking trust in, that is [...] the risks they take" (Savransky, 2017, p. 25). Thus, ideals of what bodies and bodily states are worth investing trust in, are central to both normative and counterpublic chemsex imaginaries. This paper argues that media infrastructures significantly configure what kinds of trust-risk that can circulate, and consequently, the kinds of erotic chemsex expressions that are presented and consumed.

Building from this perspective this paper asks how different modes of feeling trust-risk emerge, and how they work on the body to allow it to feel pleasure consuming some kinds of representations of chemical disinhibition while denying itself others. I follow Kane Race's distinction of chemical and digital infrastructures (Race, 2018) The 
chemical infrastructure of crystal meth, that is, its chemical formulation, the form it take, its geographical, distribution, and its modes of entering the body, allows for certain risks to be taken and pleasures to be felt. These risks and pleasure can be affective, social, viral, normative or something else. At the same time digital infrastructures allow for certain risk/pleasure-configurations of drug taking to be circulated, gain traction and become erotic objects.

Methodology the paper follows Paasonen's proposition the platformization of porn requires careful attention to the multiple transformations emerging with these infrastructures (2011). Analytically I break down the two platforms into their microsystems (Van Dijck, 2013), focusing on technology, users, governance, and content (ibid., p. 28). Methodologically, the walkthrough method (Light, Burgess, \& Duguay, 2018) is used to generate material sustains analysis that cuts across these microsystems. The material then will include platform content moderation strategies, the (in)visibility of interactivity afforded, audio-visual genre variations, the framing work done by titles and playlists, and the social erotic consumption done in the comments sections.

The paper finds that two major trust-risk chemsex configurations are at play: one informed by a normative public imaginary positioning chemical disinhibition as immoral and always dangerous, and on the other hand a counterpublic imaginary in which chemical disinhibition is a source of kinship and exploration of what bodies can do and feel. The counterpublic imaginary is able to inform erotic consumption of chemsex representations in part because of the infrastructural resistance towards the circulation of normative discourse. Practically, the conference call service, its points of access, and visual communicative affordances, achieves this by having access rely on the unreliable process of finding the forum, understanding of coded language, somewhat cumbersome downloading of software, and then, once in, having users face many-to-many visibility thus becoming invested in discretion. This way the infrastructure configures trust-risk so that the counterpublic erotics of smoke entering the lungs and needles penetrating the skin, can be enacted and consumed. On Pornhub the asynchronous engagement with video clips forms the material basis of the chemsex imaginary, along with their naming, tags, playlists organisation, and the comments that users leave. By pseudonymization of users, the infrastructure acts to establish a space in which issues of trust between users are made unimportant. However, normative public (dis)trust in chemical disinhibition can also be seen circulating and modulating the audio-visual-textual semantic structures on offer, for example when users express disgust at depicted practices.

\section{References}

Abrahamsson, S., Bertoni, F., Mol, A., \& Martín, R. I. (2015). Living with Omega-3: New Materialism and Enduring Concerns. Environment and Planning D: Society and Space, 33(1), 4-19.

Ahmed, S. (2009). Happiness and queer politics. World Picture, 3, 1-20. 
Light, B., Burgess, J., \& Duguay, S. (2018). The walkthrough method: An approach to the study of apps. New Media \& Society, 20(3), 881-900.

Macfarlane, A. (2016). Sex, drugs and self-control: why chemsex is fast becoming a public health concern. Journal of Family Planning and Reproductive Health Care, 42(4), 291-294. https://doi.org/10.1136/jfprhc-2016-101576

Paasonen, S. (2011). Carnal resonance: Affect and online pornography. MIT Press.

Platteau, T., Pebody, R., Dunbar, N., Lebacq, T., \& Collins, B. (2019). The problematic chemsex journey: a resource for prevention and harm reduction. Drugs and Alcohol Today.

Race, K. (2018). The Gay science: intimate experiments with the problem of HIV. London \& New York: Routledge.

Savransky, M. (2017). The wager of an unfinished present: notes on speculative pragmatism. In Speculative Research (pp. 43-56). Routledge.

Van Dijck, J. (2013). The culture of connectivity: A critical history of social media. Oxford University Press. 


\title{
TWO REGIMES OF TRUST: GAY MEN, VIRAL PORN AND MOLECULAR PROSTHESES
}

\author{
João Florêncio \\ University of Exeter, UK
}

We're living in viral times; ours is a time of contagion. As Tony Sampson writes in his book Virality: Contagion Theory in the Age of Networks, "the networked infrastructures of late capitalism are interwoven with the universal logic of the epidemic" (Sampson 2011 , p. 1-2). Deeply connected to contemporary biopolitics and modes of digital sociability, virality also underpins new forms of wealth creation and accumulation sustained by 21 st-century media, whilst at the same time (paradoxically, perhaps) presenting a political threat through the risk it carries of "contagious overspills" that may undo borders, nation states, institutions, ontologies, and subjectivities (ibid., p. 2). This paper draws from interviews with gay men working within and outside the porn industry, as well as from a critical engagement with depictions of (or allusions to) both antiretroviral and chemsex drugs in online pornography, in order to explore how that "universal logic of the epidemic" has actualised these two very different drug-taking regimes amongst subsections of the gay population; two drug regimes that-I arguealso imply two very different and yet co-dependent regimes of trust.

Defined by Sampson as "contagious relationality" (ibid., p. 3), in the age of memes, "fake news," hacking, epidemics, ecological and financial crises, global migration flows, antiretroviral drugs, YouTube and Pornhub, virality is at the centre of contemporary forms of both control and liberation (ibid., p. 5-6). Whilst, on the one hand, it sustains the logics of 21st-century biopolitics (antiretrovirals, hygiene, cyber security, ID and ageverification systems, etc.), on the other it also has the ability to disrupt State-sanctioned subjectivities and social assemblages, a capacity that resides in its ability to facilitate unforeseen flows of desire and affect (gay chemsex parties organised through Grindr and facilitated by Uber, biohacking, citizen journalism, Wikileaks, Anonymous, the "Arab Spring," the "Yellow Vest Movement," etc.). Echoing Deleuze and Guattari's analysis of Capitalism as a machine that decodes flows of desire only to then recode them towards its ultimate goals of capital accumulation and production for production's sake (Deleuze \& Guattari 1987), the logics of virality identified by Sampson are also behind recent developments in forms of sexual sociability practiced by gay men, and mediated by online environments and biochemical molecular prostheses. Falling under the broader umbrella of what's come to be known as "pig play"-with "pig" emerging as the "existential refrain" (Guattari 1995; 2011) that often frames the subjectivities of the gay men who take part in them-those forms of sexual sociability involve sexual risk-taking, the intentional violation of perceived boundaries between self and other, and a discovery and embrace of the porosity, penetrability, and leaky nature of bodies gendered as male. What is interesting for the purpose of this paper, is how those gay male sexual behaviours appear to have emerged in tandem with an increase in the uptake of two very different drug regimes amongst growing sections of the gay population: on the one hand, Highly-Active Antiretroviral Therapies (HAART) used either for management or prophylaxis of HIV infection; and, on the other, a very different sort of "combination regimen" comprised of recreational drugs like Crystal 
Methamphetamine ("Tina"), Gamma-Hydroxybutyric Acid (GHB) or Mephedrone ("MCAT," "meow meow") that fuel what's come to be known as "chemsex." It is then no surprise that the sexual practices associated with "pig play" have often reached public debate qualified with terms like "epidemic" (Kagan 2015; Florêncio 2016; Giorgetti et al 2017).

With that context in mind, and drawing from existing critical studies of the biopolitics of antiretroviral drugs (Dean 2015; Race 2001; 2009; 2018) and of the ways in which the development of biomedicine has recoded our understandings of the human body (Preciado 2013), I will map the complex relationship between risk and trust that is being played out in the sexual lives of 21 st-century gay men and mediated by online gay porn. In an attempt to rescue narratives of risk and trust away from contemporary financial capitalism's algorithmic attempts to calculate futures, turning them instead into creative modes of speculation on potentially-dawning queer futures that may move us away from the "quagmire of the present" (Muñoz 2009, 1; Savransky 2017), I explore how the regimes of trust associated with antiretroviral and chemsex drugs queer modern perceptions of the male body as impermeable and self-enclosed (Grosz 1994; Shildrick 1997; Longhurst 2001; Cohen 2009; Chen 2012), and how the online mediation of the sexual practices they have come to catalyse can modulate new "carnal horizons of possibility" (Paasonen 2018, 8), new futures for our bodies understood as the "interfacing of visual, semiotic, libidinal, and biochemical prosthetic flows" (Florêncio 2018, p. 282).

\section{References}

Chen, M. (2012). Animacies: Biopolitics, Racial Mattering, and Queer Affect. Durham and London: Duke University Press.

Cohen, E. (2009). A Body Worth Defending: Immunity, Biopolitics, and the Apotheosis of the Modern Body. Durham and London: Duke University Press.

Dean, T. (2015). "Mediated intimacies: Raw Sex, Truvada, and the bio politics of chemoprophylaxis." Sexualities 18(1/2): 224-246.

Deleuze, G. And F. Guattari (1987). A Thousand Plateaus: Capitalism and Schizophrenia. Minneapolis and London: University of Minnesota Press.

Florêncio, J. (2016). “Chemsex: Why is Gay Sex Causing Straight Panic?” The Conversation UK, April 12, 2016. https://theconversation.com/chemsex-why-is-gay-sexcausing-straight-panic-56541.

Florêncio, J. (2018). "Breeding Futures: Masculinity and the Ethics of CUMmunion in Treasure Island Media's Viral Loads." Porn Studies 5(3): 271-285.

Giorgetti et al (2017). "When 'Chems' Meet Sex: A Rising Phenomenon Called 'ChemSex'." Current Neuropharmacology 15(5): 762-770. 
Grosz, E. (1994). Volatile Bodies: Toward a Corporeal Feminism. Bloomington and Indianapolis: Indiana University Press.

Guattari, F. (1995). Chaosmosis: an ethico-ethics-aesthetic paradigm. Bloomington and Indianapolis: Indiana University Press.

Guattari, F. (2011). The Machinic Unconscious: Essays in Schizoanalysis. Pasadena: Semiotext(e).

Kagan, D. (2015). "Re-crisis': Barebacking, sex panic and the logic of epidemic." Sexualities 18(7): 817-837.

Longhurst, R. (2001). Bodies: Exploring Fluid Boundaries. London and New York: Routledge.

Muñoz, J. (2009) Cruising Utopia: The Then and There of Queer Futurity. New York and London: New York University Press.

Paasonen, S. (2018). Many Splendored Things: Thinking Sex and Play. London: Goldsmiths Press.

Preciado. P. (2013). Testo Junkie: Sex, Drugs, and Biopolitics in the Pharmacopornographic Era. New York: The Feminist Press.

Race, K. (2001). "The Undetectable Crisis: Changing Technologies of Risk." Sexualities 4(2): 167-189.

Race, K. (2009). Pleasure Consuming Medicine: The Queer Politics of Drugs. Durham and London: Duke University Press.

Race, K. (2018). The Gay Science: Intimate Experiments with the Problem of HIV. London and New York: Routledge.

Sampson, T. (2011). Virality: Contagion Theory in the Age of Networks. Minneapolis and London: University of Minnesota Press.

Savransky, M. (2017). "The wager of an unfinished present: Notes on speculative pragmatism." In Alex Wilkie, Martin Savransky and Marsha Rosengarten (eds), Speculative Research: The Lure of Possible Futures, 25-38. London and New York: Routledge.

Shildrick, M. (1997). Leaky Bodies and Boundaries: Feminism, Postmodernism and (Bio)Ethics. London and New York: Routledge. 


\section{'BEFORE PrEP, AND NOW...IT'S LIKE DIFFERENT WORLDS': ONTOLOGIES OF CHEMSEX}

Dean Murphy

University of Sydney, Australia

Kane Race

University of Sydney, Australia

Kiran Pienaar

Monash University, Australia

Toby Lea

Catholic University of Applied Sciences, Germany, \& University of New South Wales, Australia

In the period following the approval of the combination antiretroviral drug Truvada for HIV pre-exposure prophylaxis (PrEP) by the US Food and Drug Administration, several actors sought to denigrate both the idea and use of PrEP on the basis of its imputed association with, or production of, sexual pleasure and uninhibited 'hedonism'. 'Let's be honest: [PrEP]'s a party drug', Michael Weinstein, president of the AIDS Healthcare Foundation of Los Angeles, famously declared. This figuration of PREP can be read against a backdrop in which the historical associations between gay sex and pleasure, drugs and death are both highlighted and problematised (Bersani, 1987).

In this paper we explore the possibilities that emerge when we take the risk of affirming Weinstein's claim. We argue that this approach may lead to certain practical benefits and pragmatic insights about PrEP's use, meaning, identities and effects. It might also make gay sex and drug practices more intelligible, and easier for participants to acknowledge and think about. If the identity of drugs is understood to emerge, like other technologies, in association with the networks in which they are embedded, then the role that PrEP is beginning to play in sex 'partying' might be seen not as something to be avoided, but rather something that might provide greater clarity about the stigmatised, criminalised and intensively demonised sex, drug and digital practices that constitute chemsex events.

As Kane Race (2018) has argued, digital infrastructures have transformed sexual practices and relations among men, and produced new ways of negotiating HIV risk, many of which involve antiretroviral-based subjectivities and knowledges. In this paper we explore how PrEP is mediating chemsex for HIV-negative men. In particular, we conceive chemsex in terms of an 'event network', a term that Emilie Gomart and Antoine Hennion (1999) coined to think about the arrangements put in place to enable certain passionate attachments (to music and/or to drugs) to emerge. Inherent in this approach is a shift in attention away from the human subject, the chemsex participant, as the orchestrator of sovereign action, and towards chemsex, conceived of as a conjunctural event, i.e. a 'concrete activity whose modes, practices and dispositifs can 
be described... [and] in which the relevant subjects, objects and social groupings are co-produced'.

Our analysis draws on interviews with gay and queer participants who use PrEP, part of a larger sample of LGBTQ participants who use various medications and drugs to transform aspects of their sexual and/or gender experience. Over $20 \%$ of HIV-negative men in Australia's key urban centres of Sydney and Melbourne report that they are currently taking PrEP (Holt et al., 2018). This growing use of PrEP represents an important opportunity to analyse the transformations in gay sexual and digital practices and cultures that are currently taking place.

Participants in these interviews attributed a range of effects to the antiretroviral drugs that comprise PrEP, including effects that biomedicine and regulatory authorities rarely consider or acknowledge. In particular, they often reported that using PrEP had reduced their anxieties about HIV infection and had opened up the possibility of participating in practices they had previously avoided. The suggestion that PrEP can reduce concerns about HIV corresponds with the findings of other studies (Gafos et al., 2018; Koester et al., 2017). In this paper, we venture that PrEP may be transforming sex in more significant ways. Notably, for a number of participants, trust in PrEP's effectiveness has transformed sex into something different from what it had been prior to taking PrEP. In this sense, analogies can be drawn between PrEP and a range of other drugs consumed by gay men in sexual settings, including recreational drugs, which - like PrEP - are roundly problematised for their purported 'disinhibitory' effects (Race, 2009, p. 176).

HIV-negative participants in our study described how PrEP provided an opportunity for them to seek out and participate in chemsex activities, typically arranged via hookup apps and other digital devices. For some participants, new interests and attachments to chemsex emerged only after commencing PrEP, while for others (such as those who had engaged in sexualised drug use previously) PrEP enabled a different attachment to chemsex - one less concerned with vigilance (of practices, and of sexual partners), thereby enabling the drugs usually associated with chemsex to work 'better'. The sense of control or trust invoked by PrEP users can be distinguished from the control or selfmastery commonly associated with the sovereign figure of the neoliberal subject, however (Race, 2017; Stengers \& Latour, 2011). Rather, trust/control is emergent; emerging from particular arrangements or event-networks.

Gommart and Henion (1999) argue that active work is undertaken, and particular arrangements are put in place, for participants to be 'moved' and give effect to their passions. Similarly, we found our participants engaged in a process of making particular social and material arrangements to enable a 'letting go'; through this process they became prepared to be affected in particular (though not always predetermined) ways. Chemsex encounters can be approached, in other words, as entailing specific kinds of abandonment and dispossession, created through actions that are intricate and regularised enough to allow participants to 'let themselves go'. Neither PrEP, not chemsex, are stable; they are intra-active phenomena (Barad, 2003). What is emerging now, we argue, is not simply 'more chemsex' but new ontologies of chemsex, which are themselves in a process or state of constant transformation. 


\section{References}

Barad, K. (2003). Posthumanist Performativity: Toward an Understanding of How Matter Comes to Matter. Signs, 28(3), 801-831.

Bersani, L. (1987). Is the Rectum a Grave? October, 43: 197-222.

Gafos, M., Horne, R., Nutland, W., Bell, G., Rae, C., Wayal, S., . . McCormack, S. (2018). The Context of Sexual Risk Behaviour Among Men Who Have Sex with Men Seeking PrEP, and the Impact of PrEP on Sexual Behaviour. AIDS and Behavior. doi: 10.1007/s10461-018-2300-5. [Epub ahead of print]

Gomart, E., \& Hennion, A. (1999). A sociology of attachment: music amateurs, drug users. The Sociological Review, 47(S1), 220-247.

Holt, M., Lea, T., Mao, L., Kolstee, J., Zablotska, I., Duck, T., . . Prestage, G. (2018). Community-level changes in condom use and uptake of HIV pre-exposure prophylaxis by gay and bisexual men in Melbourne and Sydney, Australia: results of repeated behavioural surveillance in 2013-2017. The Lancet HIV, 5(8), e448-e456.

Koester, K., Amico, R. K., Gilmore, H., Liu, A., McMahan, V., Mayer, K., . . Grant, R. (2017). Risk, safety and sex among male PrEP users: time for a new understanding. Culture, Health \& Sexuality, 19(12), 1301-1313.

Race, K. (2009). Pleasure Consuming Medicine: The Queer Politics of Drugs. Durham \& London: Duke University Press.

Race, K. (2017). Thinking with pleasure: Experimenting with drugs and drug research. International Journal of Drug Policy, 49, 144-149.

Race, K. (2018). The Gay Science: Intimate Experiments with the Problem of HIV. London \& New York: Routledge.

Stengers, I., \& Latour, B. (2011). Thinking with Whitehead: A free and wild creation of concepts. Cambridge, MA: Harvard University Press. 